\title{
Nimodipine reduces delayed cerebral vasospasm after intracranial tumor surgery: a retrospective study
}

\section{Ying Yu}

Jilin University First Hospital

\section{Yunqian Li}

Jilin University First Hospital

Zheng Jin

Jilin University First Hospital

\section{Shuai Zhao}

Jilin University First Hospital

Fan Chen ( $\nabla$ professorchen@foxmail.com )

First Hospital of Jilin University https://orcid.org/0000-0002-5739-2776

Research article

Keywords: cerebral vasospasm, ischemia, nimodipine, intracranial tumor surgery

Posted Date: September 24th, 2020

DOI: https://doi.org/10.21203/rs.3.rs-32931/v3

License: (a) (i) This work is licensed under a Creative Commons Attribution 4.0 International License. Read Full License 


\section{Abstract}

Background $\mathbb{X}$ Cerebral vasospasm (CVS) is a serious neurosurgical complication. This retrospective study was performed to analyze if nimodipine can improve prognosis and reduces ischemia secondary to delayed CVS after intracranial tumor surgery.

Methods $\$ Retrospective analysis of 94 patients with an anterior cranial fossa tumor and underwent intracranial tumor surgery was performed, with 42 cases treated with normal saline and 52 cases treated with nimodipine solution. Transcranial Doppler ultrasonography was used to measure velocity in the middle cerebral artery (MCA) and the distal extracranial internal carotid artery (elCA). An examination was conducted 1 day before surgery and 1, 3, 5, 7, and 14 days after surgery. Follow-up was performed using the Glasgow Outcome Scale (GOS) 3 months after discharge.

Results $₫$ We showed that in the nimodipine group, CVS occurred in 13 (25\%) patients who did not have CVS in the first three days after operation; nine patients had CVS between 4 and 7 days, and 4 had CVS between 8 and 14 days. In the normal saline group, nineteen (45\%) patients had CVS, 3 presented with CVS within 3 days, 11 between 4-7 days and 5 between 8-14 days. A significant difference in the occurrence of CVS was observed between the two groups. Preoperative and postoperative the MCA velocities were compared, revealing a significant change in the normal saline group $(P<0.05)$ but not in the nimodipine group. Furthermore, significant differences in the outcome were observed between the two groups at the 3-month follow-up $(P<0.05)$.

Conclusions $₫$ Nimodipine markedly improves prognosis and significantly reduces ischemia secondary to delayed CVS after intracranial tumor surgery, as well as the risks of mortality and morbidity.

\section{Introduction}

Cerebral vasospasm (CVS) is a serious neurosurgical complication[1, 2]. Currently, studies are focused on CVS induced by subarachnoid hemorrhage (SAH) caused by arterial aneurysm and traumatic SAH $[3,4]$. There are a few cases that have been reported regarding delayed CVS after intracranial tumor surgery.[57]. The intracranial low-density zone visualized with CT caused by CVS is usually misdiagnosed as surgical injury or postoperative brain edema, leading to incorrect treatment of patients and a poorer prognosis. It has been shown that the incidence of CVS after intracranial tumor surgery is relatively high (22-49\%), especially if an immediate diagnosis and/or treatment is delayed, consequently decreasing the effectiveness of surgery[8,9].

Nimodipine is a second-generation dihydrotestosterone pyridine class calcium antagonist, and nimodipine has high lipophilicity, which makes it rapidly cross the blood-brain barrier. The main mechanism of nimodipine is selective blockade of intracellular calcium flow through L-type calcium channels[10]. Nimodipine is considered the first choice for the prevention of CVS after SAH and has been approved in the United States[11], Canada[12] and other countries[13]. Prophylactic use of nimodipine during craniotomy is effective in the prevention of neurological dysfunction after surgery[14]. 
This study retrospectively analyzed the 5-year clinical data of 94 patients with an anterior cranial fossa tumor treated with normal saline and treated with nimodipine solution. Here, we report the effects of nimodipine on CVS after intracranial tumor surgery.

\section{Material And Methods}

This study was reviewed and approved by the Ethics Committee of the first hospital of Jilin University. All patients provided informed consent. Patients with an anterior cranial fossa tumor who were treated in our hospital from January 2011 to May 2012 were included in this study. The inclusion criteria were as follows: confirmed diagnosis of an anterior cranial fossa tumor; consent to undergo intracranial tumor surgery; the performance of the relevant research; and no serious dysfunction of the heart, lung, liver or kidney.The exclusion criteria were as follows: severe coagulopathy, hypertension, atherosclerosis, diabetes, postoperative bleeding after intracranial tumor craniotomy, malignant cerebral edema, or a reopening of the craniotomy site. All patients were followed up for at least 3 months.

A total of 94 patients were included in the study. Fifty patients were male, and forty-four were female. Patients ranged in age from 17 to 80 years, and the average age of these patients was 49.6 years. In the nimodipine group, there were 27 males and 25 females, while in the normal saline group, there were 23 males and 19 females. Patients ranged in age from 17-80 years. The average age in the nimodipine group and the normal saline group was 48.9 and 49.8 years, respectively. No significant difference in sex or age was observed between the two groups of patients. The pathological diagnoses included meningioma $(n=65)$, glioma $(n=18)$, brain metastases $(n=10)$ and schwannoma $(n=1)$.

\section{Grouping}

Surgery was performed under general anesthesia, and microsurgical techniques were applied to avoid stretching the brain tissue and blood vessels as little as possible. All patients performed surgery by subfrontal approach, enlarged subfrontal approach, or pterional approach. Careful hemostasis was performed if hemorrhaging occurred during surgery. All patients did not use any vasoactive agent a week before surgery.

Patients were randomly divided into two groups based on whether they were treated with nimodipine: 1 . The nimodipine group ( $n=52)$ received nimodipine (Bayer, Germany) solution ( $10 \mathrm{mg} / 50 \mathrm{~mL}$, during surgery and for 7 days after surgery) and tablets ( $30 \mathrm{mg} /$ per tablet; from the 8th day to the 14th day after surgery). All intracranial tumors were totally resected under a microscope. Varying degrees of vascular invasion were observed among all patients, especially in sellar tumors. The surgical field was soaked in diluted nimodipine solution (stock: normal saline=1:5) for 10 minutes囚including the exposed nerve and blood vessel, especially the optic nerve and the MCA. In sellar region procedures, the optic nerve and middle cerebral artery (MCA) were exposed(Fig. 1A), and nimodipine lavage of the optic nerve and MCA was administered(Fig. 1B). After surgery, the patients were continuously perfused with nimodipine at an initial dose of $0.5 \mathrm{mg} / \mathrm{h}$ via a microinfusion pump (Zhejiang University Medical Instrumental Co. Ltd; TypeWZ-50C2); then, the dose was gradually increased to $2 \mathrm{mg} / \mathrm{h}$ if the patient tolerated the treatment 
withouthypotension and was continuously infused for 7 days. After soaking, the optic nerve and MCA wereviewed in different colors: the MCA was viewed as purple-red, and the optic nerve was viewed as yellowish-white. Next, patients were given oral nimodipine tablets $(60 \mathrm{mg} / 4 \mathrm{~h})$ for 7 days. 2 . The normal saline group $(n=42)$ : the surgical field was soaked in normal saline for 10 minutes. In addition to the continued use of nimodipine after surgery in the nimodipine group, the normal saline followed by the same treatment dose and schedule as the nimodipine group after surgery.

Patients in both groups also received standard care, including, lowering of intracranial pressure, hemostasis, and prevention of infection.

\section{Modified Fisher Scale}

Brain computed tomography (CT) was performed on the day of surgery. Classification of the amount and distribution of SAH was based on the modified Fisher scale[15]. Grade 0: No SAH or no intraventricular blood; Grade I: Thin diffuse or focal subarachnoid blood but without intraventricular blood; Grade II: Thin diffuse or local subarachnoid blood with intraventricular blood; Grade III: Thick focal or diffuse subarachnoid blood but without intraventricular blood; and Grade IV: Thick focal or diffuse subarachnoid blood with intraventricular blood.

\section{Measurement of cerebral blood flow}

Transcranial Doppler ultrasonography (TDU) (Multi-Dop X2, DWL, Germany) was used. Patients were placed in the supine position. A $2.0 \mathrm{MHz}$ probe was used to measure the velocity of MCA at the temporal window (the zygomatic arch from the orbit to the outer edge of the auricular front). The velocity of the distal extracranial internal carotid artery (eICA) was measured just below the mandibular angle as well. All measurements were made by the same doctor. An examination was performed 1 day prior to surgery and at $1,3,5,7$, and 14 days after the surgery.

\section{Clinical presentations of cerebrovascular spasm}

1. Symptoms fluctuated or were progressively aggravated. 2. Changes in consciousness: Patients became drowsy or comatose or went from being comatose to being alert and then became comatose again. 3. Focal neurological signs were evaluated. 4. Patients were monitored for symptoms of increased intracranial pressure. 5. No obvious seizure, hypoxia, or electrolyte imbalance were observed apart from the possibilities of cerebral edema, delayed hemorrhage, infections or hydrocephalus after surgery. These developments also included the first four symptoms but not the CVS. A diagnosis was made if patients presented with one of the first four symptoms and signs plus the last sign[2]. Occurrence of CVS was confirmed if MCA velocity was more than $120 \mathrm{~cm} /$ seconds, and the Lindegaard index (a ratio of the MCA velocity to the ipsilateral eICA velocity) as detected by TDU was more than 3 .

\section{Prognosis}


Follow-up was performed using the Glasgow Outcome Scale (GOS) three months after discharge[16]. Grade I: Dead; Grade II: Persistent vegetative state; Grade III: Severe disability; Grade IV: Moderate disability; and Grade V: Good recovery.

\section{Statistical analyses}

Statistical analyses were performed using SPSS software (version 19.0; SPSS Inc., Chicago, IL, USA). Count data were analyzed by a $\chi^{2}$ test. The Student's $t$ test was used for comparison of measurement data that were normally distributed and had homogeneity of variance. A rank-sum test was applied for the analysis of measurement data that were not normally distributed and lacked homogeneity of variance. $P<0.05$ was considered statistically significant.

\section{Results}

\section{General information}

Clinical presentations after surgery: One patient had altered consciousness, two had impairment of the visual field, and two had psychiatric symptoms, two patients in the control group, three patients in the treatment group. After surgery, no reopening of the craniotomy site occurred, and no death or complications such as intracranial or wound infection, intracranial fluid, cerebrospinal fluid leakage occurred after surgery.

CVS occurred in 32 patients in the two groups. For the 32 patients, TDU examination revealed that the average MCA velocity of the nimodipine group was $154.2 \mathrm{~cm} /$ seconds, and the average MCA velocity of the normal saline group was $182.6 \mathrm{~cm} /$ seconds. The velocity in 19 of 32 patients was more than 200 $\mathrm{cm} / \mathrm{s}$, the average MCA velocity of the nimodipine group among the 19 patients was $207.1 \mathrm{~cm} / \mathrm{seconds}$, and the average MCA velocity of the normal saline group was $223.3 \mathrm{~cm} /$ seconds. Cerebral infarction was observedby CT/MRI in 10 patients at $48 \mathrm{~h}$ after the occurrence of CVS, worsened headache was found in 23 patients, reduced consciousness or coma was identified in 17 patients, motor dysfunction of the limbs became aggravated in 13 patients, and newly found motor dysfunction of the limbs was seen in 7 patients.

On the day after surgery, intracranial CT examination revealed no hematoma, ischemia, and contusion or lacerated lesions in the brains.

No significant difference in the modified Fisher scale scores was found when 5 individual grades were compared separately between the nimodipine group and the normal saline group $(P>0.05$, Table 1$)$.

In the nimodipine treatment group, CVS was found in 13 (25\%) patients, and none occurred during the first three days after the operation. Nine patients had CVS between 4 and 7 days, and 4 had CVS between 8 and 14 days. TDU examination of the nimodipine group prior to surgery indicated that the MCA velocity was no more than $120 \mathrm{~cm} /$ seconds (Fig. 2A). MCA velocity was slightly higher in the nimodipine group 
after surgery than that prior to surgery; however, it was no more than $120 \mathrm{~cm} /$ seconds (Fig. 2B). In contrast, in the normal saline group, 19 (45\%) patients had CVS, 3 presented with CVS within 3 days, 11 within 4-7 days and 5 between 8 and 14 days. In meningioma patients, CVS was found in $9(25 \%, 9 / 36)$ patients in the nimodipine treatment group and $14(48.28 \%, 14 / 29)$ patients in the normal saline group. In glioma patients, CVS was found in $2(20 \%, 2 / 10)$ patients in the nimodipine treatment group and 4 (50\%, $4 / 8)$ patients in the normal saline group. In metastases patients, CVS was found in $2(33.33 \%, 2 / 6)$ patients in the nimodipine treatment group and $1(25 \%, 1 / 4)$ patients in the normal saline group(Figure 4$)$. Compare CVS of different tumors patients between the two groups the occurrence of CVS was no significant difference. TDU examination of the normal saline group prior to surgery indicated that the MCA velocity was no more than $120 \mathrm{~cm} /$ seconds (Fig. 3A). TDU examination of the normal saline group after surgery revealed that the MCA velocity was more than $120 \mathrm{~cm} / \mathrm{seconds}$ (Fig. 3B). A significant difference in the occurrence of CVS was observed between the two groups $(P<0.05$; Table 2$)$.

\section{Comparison of the MCA velocity prior to surgery and after surgery in the nimodipine group and the normal saline group}

There was a significant change between preoperative and postoperative the MCA velocity in the normal saline group $(P<0.05$, Table 3); however, no significant changes were observed between preoperative and postoperative the MCA velocity in the nimodipine group.

\section{Comparison of prognoses between the nimodipine group and the normal saline group}

Grade V indicated a good prognosis, and grades I, II and III were defined as a poor prognosis. The prognosis of IV is better than that of III, but it is worse than that of V. Seventy patients had a good prognosis, 24 patients had a poor prognosis (one of these patients with a poor prognosis died). A followup was performed three months after surgery and showed that in the nimodipine group, 3 patients were grade II, 6 were grade III, 16 were grade IV, and 27 were grade V. In the normal saline group, 1 patient was grade I, 2 patients were grade II, 12 patients were grade III, 17 patients were grade IV and 10 patients were grade V. (Table 4). In the nimodipine group, 43 patients had a good prognosis, and 9 had a poor prognosis. In the normal saline group, 27 had a good prognosis and 15 had a poor prognosis $(P<0.05$; Table 4). The postoperative complication could be prevented by the administration of nimodipine.

\section{Discussion}

In the present study, we showed that administration of nimodipine during and after surgery can effectively prevent the occurrence of delayed CVS and improves the prognosis of CVS. After resecting the tumor, diluted nimodipine (stock solution: normal saline=1:5) was soaked into the surgical field for 10 minutes, and then nimodipine was continuously infused via a micropump. For patients weighing less than $70 \mathrm{~kg}$ or having unstable blood pressure, the starting dose was $0.5 \mathrm{mg} / \mathrm{h}$, and if the patient tolerated this dose well, the dose was increased to $1 \mathrm{mg} / \mathrm{h}$ after $2 \mathrm{~h}$. For patients weighing more than $70 \mathrm{~kg}$, the starting dose was $1 \mathrm{mg} / \mathrm{h}$, and if the patients tolerated this dose well, the dose was increased to $2 \mathrm{mg} / \mathrm{h}$ after $2 \mathrm{~h}$ and administered for 14 days. Thereafter, nimodipine was administered orally $(60 \mathrm{mg}$, once a 
day, for 7 days). CVS after intracranial tumor craniotomy is a multifactorial clinical syndrome. CVS is caused by an extreme contraction of the arteries and tense vascular smooth muscle[14]. The mechanisms underlying CVS remain unclear; it may be multifactorial and involve a complicated pathological process. Potential causes of CVS are as follows: 1. mechanical stimulation such as damage, compression or stretching of the blood vessels during surgery, leading to the blood flowing into the subarachnoid space and subsequent occurrence of CVS occurs[17]; 2. vascular wall injury caused by compression of the vascular wall and vascular wall malnutrition[18]; 3. damage caused by the oxidation of hemoglobin to methemoglobin and release of oxygen free radicals[19]; 4. constriction of the blood vessels caused by vasoactive substances[20]; 5 . increased intracranial pressure, the overdose of dehydration drugs and insufficient supply of blood volume[21]; and 6. inflammation and immune reactions of blood vessel walls[6,22,23]. The common final pathway arising from all the above factors stated is a change in the permeability of smooth muscle cells in the blood vessels, an increase in calcium influx and release of calcium ion from intracellular calcium stores, leading to an overload of free calcium in the cytosol[24]. When a critical constriction concentration is reached following the opening of calcium channels, extracellular calcium enters the cells and is released from the calcium stores, leading to an increase in the concentration of free calcium in the cytosol; thus, vasospasm occurs[25]. Therefore, calcium overload is believed to be the most important phenomenon during the generation of vasospasm.

There are two types of calcium channels, voltage-dependent and receptor-operated[26]. The former is located in the cell membrane of heterologous multimeric transmembrane proteins. These channels are activated at depolarized membrane potentials and are the source of the "voltage-dependent" epithet. The concentration of calcium ( $\mathrm{Ca}^{2+}$ ions) is normally several thousand times higher outside of the cell than inside. Activation of particular VDCCs allows $\mathrm{Ca}^{2+}$ to rush into the cell, which depending on the cell type, results in activation of calcium-sensitive potassium channels, muscular contraction, excitation of neurons, upregulation of gene expression, or release of hormones or neurotransmitters. The opening of this type of channel is related to voltage and occurs due to the depolarization of the smooth muscle cell membrane after the channel is activated and excited[27]. The opening of the latter channel is caused by the stimulation of receptors of the cell membrane by certain substances, such as 5-hydroxytryptamine and adrenalin. Subsequently, calcium influx increases, and calcium release occurs, leading to vasospasm caused by the abovementioned mechanism. These findings provide evidence for the potential prevention of CVS using calcium channel blockers.

It has been shown that nimodipine significantly reduced symptoms caused by secondary ischemia after $\mathrm{SAH}$; consequently, the risks of death and paralysis caused by CVS were markedly reduced[28]. Currently, nimodipine is considered as the first choice for the prevention of CVS after SAH. Nimodipine is a secondgeneration dihydrotestosterone pyridine class calcium antagonist with the highest lipid solubility[29]. High lipophilicity of nimodipine facilitates its movement through the blood-brain-barrier, and nimodipine is also highly selective for vascular smooth muscle due to the dihydrotestosterone pyridine ring[30]. Moreover, nimodipine can block L-type voltage-dependent calcium channels in the cell membrane of vascular smooth muscles, effectively inhibiting calcium influx and simultaneously activating $\mathrm{Ca}^{2+}{ }^{2}$ ATP, 
which promotes depletion of cytoplasmic calcium and enhances calcium intake and storage from the mitochondria and endoplasmic reticulum, thereby regulating the concentration of intracellular $\mathrm{Ca}^{2+}$ and maintaining normal physiological functions[31]. Moreover, nimodipine can inhibit aggregation of platelets and leukocytes, reducing erythrocyte rigidity and blood viscosity and preventing the release of 5$\mathrm{HT}$ and arachidonic acid and other vasoactive substances that cause vasoconstriction[32].

In addition, nimodipine can significantly improve cerebral blood circulation after brain injury, preventing secondary brain damage and promoting brain function recovery. Nimodipine lavage can effectively improve the prognosis of secondary cerebral vasospasm after SAH[33-35]. Our findings revealed that infusion and oral intake of nimodipine after nimodipine lavage during surgery are effective in the prevention of the development of delayed CVS after intracranial tumor craniotomy. The incidence of CVS in the nimodipine group (25\%) was significantly lower than that in the normal saline group (45\%). In addition, the MCA velocity was significantly lower in the nimodipine group than in the normal saline group after surgery. Prognoses appeared to be remarkably improved in the nimodipine group.

To date, regarding the diagnosis of CVS after intracranial tumor craniotomy, digital subtraction angiography (DSA) and TDU are believed to be effective CVS detection methods. DSA had been a gold standard for the diagnosis of CVS[36]. However, if the blood vessel is too small to be detected by DSA, misdiagnosis of CVS might occur[37]. Because DSA is an invasive examination and could produce risks such as iatrogenic stroke and rupture of the blood vessels, the application of DSA is limited for the detection of CVS[26, 38]. Additionally, TDU has the advantage of being economical, non-invasive, realtime, and repeatable, offering continuous monitoring with high sensitivity and specificity; thus, TDU has become the first-line procedure in the detection of CVS[39]. Blood flow velocity $\left(\mathrm{V}_{\mathrm{BF}}\right)$ is determined by cerebral blood flow (Q) and the diameter of cerebral blood vessels (D). The formula is as follows: $V_{B F}=4$ $\mathrm{Q} / \mathrm{D}^{2}$, with the velocity being inversely proportional to the diameter when blood volume does not change[40]. Smaller blood vessels have faster blood flow velocity; therefore, hemodynamic changes, such as high velocity and high resistance, can occur. Thus, the extent of blood vessel narrowing can be estimated by the alteration of blood flow velocity. Moreover, the MCA is the best blood vessel for monitoring CVS[41, 42]. The human MCA is a terminal branch of the ICA, has few collateral branches and has a long and straight stem. The MCA is easily detected, has high specificity, and its diameter is negatively correlated with the blood flow velocity and is positively correlated with vasospasms. Based on these facts, the MCA is typically examined to detect CVS.

In this study, blood flow velocity prior to CVS was measured as baseline velocity and was compared with that after surgery at different time points. Furthermore, comparing changes in blood flow velocity in the MCA allows the objective detection of CVS. However, different operators of TDU might obtain different results due to unavoidable subjective factors such as the variable angle of the ultrasound probe that was used[43]. In this study, the same doctor performed TDU examinations in all patients, which made the examination data reliable. Our results showed that TDU can be effectively used for the diagnosis of CVS after intracranial tumor surgery. If the flow velocity in the MCA is more than $120 \mathrm{~cm} / \mathrm{s}$, and Lindegaard index is more than 3 , a diagnosis of CVS is confirmed. 
We showed that the application of nimodipine during and after surgery can effectively prevent the occurrence of delayed CVS and improve the prognosis of CVS. Notably, the retrospective cases in our study were limited. If larger sample sizes are available, general problems can be studied more clearly.

\section{Conclusions}

Nimodipine can significantly reduce ischemia secondary to CVS after intracranial surgery; consequently, it markedly reduces the risks of mortality and morbidity and improves prognoses.

\section{Declarations}

Ethics approval and consent to participate: This trial was approved by the local ethics committee at First hospital of Jilin University (2011-041). Informed written consent was taken from all participants.

Consent for publication: Not applicable.

Availability of data and materials: All data generated or analyzed during this study are included in this published article.

Competing interests: The authors declare that they have no competing interests.

Funding: No funding was received for this research.

Authors' Contributions: FC is the guarantor of integrity of the entire study. YY and LYQ gave the study concepts and designed the study. YY, YQL, ZJ, SZ and FC did the literature research. YY performed the data analysis. YY performed the statistical analysis. YY and FC prepared the manuscript draft and FC did edit the final manuscript. All co-authors approved the final submitted manuscript.

Acknowledgments: None

\section{List Of Abbreviations}

CVS: cerebral vasospasm

MCA: middle cerebral artery

elCA: extracranical internal carotid artery

GOS: Glasgow Outcome Scale

SAH: subarachnoid haemorrhage

CT: computed tomography

TDU: Transcranial Dopper ultrasonography 
VDCCs: Voltage-dependent calcium channels

DSA: digital subtraction angiography

$\mathrm{V}_{\mathrm{BF}}$ : Blood flow Velocity

\section{References}

1. Cho SY, Lee DH, Shin HS, Lee SH, Koh JS, Jung WS, Moon SK, Park JM, Ko CN, Kim H et al: The efficacy and safety of acupuncture for cerebral vasospasm after subarachnoid hemorrhage: study protocol for a randomized controlled trial. Trials 2015, 16:68.

2. Siasios I, Kapsalaki EZ, Fountas KN: Cerebral vasospasm pharmacological treatment: an update. Neurology research internationa/2013, 2013:571328.

3. Dabus G, Nogueira RG: Current options for the management of aneurysmal subarachnoid hemorrhage-induced cerebral vasospasm: a comprehensive review of the literature. Interventional neurology 2013, 2(1):30-51.

4. Kramer DR, Winer JL, Pease BA, Amar AP, Mack WJ: Cerebral vasospasm in traumatic brain injury. Neurology research internationa/2013, 2013:415813.

5. Shimoda M, Oda S, Tsugane R, Sato O: Intracranial complications of hypervolemic therapy in patients with a delayed ischemic deficit attributed to vasospasm. Journal of neurosurgery 1993, 78(3):423-429.

6. Aoki N, Origitano TC, al-Mefty 0: Vasospasm after resection of skull base tumors. Acta neurochirurgica 1995, 132(1-3):53-58.

7. Yu Y, Dong Z, Chen D, Chen F: Pediatric Giant Craniopharyngioma: Surgical Field Soak in Diluted Nimodipine Solution Reduces Cerebral Vasospasm. World neurosurgery 2020, 141:113-114.

8. Origitano TC, al-Mefty O, Leonetti JP, DeMonte F, Reichman $\mathrm{OH}$ : Vascular considerations and complications in cranial base surgery. Neurosurgery 1994, 35(3):351-362; discussion 362-353.

9. el Hendawy M, Wronski J, Juniewicz H, Szarek W, Wojda J: Cerebral vasospasm detection by TCD after supratentorial brain tumours surgery. Neurologia i neurochirurgia polska 2000, 34(6 Suppl):114123.

10. Lin RJ, Klein-Fedyshin M, Rosen CA: Nimodipine improves vocal fold and facial motion recovery after injury: A systematic review and meta-analysis. The Laryngoscope 2019, 129(4):943-951.

11. Mayberg MR, Batjer HH, Dacey R, Diringer M, Haley EC, Heros RC, Sternau LL, Torner J, Adams HP, Jr., Feinberg W et al: Guidelines for the management of aneurysmal subarachnoid hemorrhage. A statement for healthcare professionals from a special writing group of the Stroke Council, American Heart Association. Circulation 1994, 90(5):2592-2605.

12. Findlay JM: Current management of aneurysmal subarachnoid hemorrhage guidelines from the Canadian Neurosurgical Society. The Canadian journal of neurological sciences Le journal canadien des sciences neurologiques 1997, 24(2):161-170. 
13. Scheller C, Richter HP, Engelhardt M, Koenig R, Antoniadis G: The influence of prophylactic vasoactive treatment on cochlear and facial nerve functions after vestibular schwannoma surgery: a prospective and open-label randomized pilot study. Neurosurgery 2007, 61(1):92-97; discussion 97-98.

14. Findlay JM, Nisar J, Darsaut T: Cerebral Vasospasm: A Review. The Canadian journal of neurological sciences Le journal canadien des sciences neurologiques 2016, 43(1):15-32.

15. Frontera JA, Claassen J, Schmidt JM, Wartenberg KE, Temes R, Connolly ES, Jr., MacDonald RL, Mayer SA: Prediction of symptomatic vasospasm after subarachnoid hemorrhage: the modified fisher scale. Neurosurgery 2006, 59(1):21-27; discussion 21-27.

16. Hall K, Cope DN, Rappaport M: Glasgow Outcome Scale and Disability Rating Scale: comparative usefulness in following recovery in traumatic head injury. Archives of physical medicine and rehabilitation 1985, 66(1):35-37.

17. Otani N, Takasato Y, Masaoka H, Hayakawa T, Yoshino Y, Yatsushige H, Miyawaki H, Sumiyoshi K, Chikashi A, Takeuchi S et al: Surgical outcome following decompressive craniectomy for poor-grade aneurysmal subarachnoid hemorrhage in patients with associated massive intracerebral or Sylvian hematomas. Cerebrovascular diseases (Basel, Switzerland) 2008, 26(6):612-617.

18. Vapaatalo H, Mervaala E: Clinically important factors influencing endothelial function. Medical science monitor : international medical journal of experimental and clinical research 2001, 7(5):10751085.

19. Jabbarli R, Reinhard M, Niesen WD, Roelz R, Shah M, Kaier K, Hippchen B, Taschner C, Van Velthoven $\mathrm{V}$ : Predictors and impact of early cerebral infarction after aneurysmal subarachnoid hemorrhage. European journal of neurology 2015, 22(6):941-947.

20. Szekeres M, Dezsi L, Nadasy GL, Kaley G, Koller A: Pharmacologic inhomogeneity between the reactivity of intramural coronary arteries and arterioles. Journal of cardiovascular pharmacology 2001, 38(4):584-592.

21. Jabbarli R, Reinhard M, Roelz R, Shah M, Niesen WD, Kaier K, Taschner C, Weyerbrock A, Van Velthoven V: Early identification of individuals at high risk for cerebral infarction after aneurysmal subarachnoid hemorrhage: the BEHAVIOR score. Journal of cerebral blood flow and metabolism: official journal of the International Society of Cerebral Blood Flow and Metabolism 2015, 35(10):1587-1592.

22. Almubaslat $M$, Africk $C$ : Cerebral vasospasm after resection of an esthesioneuroblastoma: case report and literature review. Surgical neurology 2007, 68(3):322-328; discussion 328.

23. Jacob JT, Hunt $\mathrm{CH}$, Wijdicks EF, Rabinstein AA, Cloft $\mathrm{H}$, Link MJ: Diffuse cerebral vasospasm after resection of a posterior fossa ependymoma. Neurocritical care 2011, 14(1):86-90.

24. Li W, Zheng T, Altura BT, Altura BM: Antioxidants prevent elevation in $[\mathrm{Ca}(2+)](i)$ induced by low extracellular magnesium in cultured canine cerebral vascular smooth muscle cells: possible relationship to $\mathrm{Mg}(2+)$ deficiency-induced vasospasm and stroke. Brain research bulletin 2000, 52(2):151-154. 
25. Wellman GC: lon channels and calcium signaling in cerebral arteries following subarachnoid hemorrhage. Neurological research 2006, 28(7):690-702.

26. Tsunoda Y: Receptor-operated Ca2+ signaling and crosstalk in stimulus secretion coupling. Biochimica et biophysica acta 1993, 1154(2):105-156.

27. Catterall WA, Swanson TM: Structural Basis for Pharmacology of Voltage-Gated Sodium and Calcium Channels. Molecular pharmacology 2015, 88(1):141-150.

28. Dorhout Mees SM, Rinkel GJ, Feigin VL, Algra A, van den Bergh WM, Vermeulen M, van Gijn J: Calcium antagonists for aneurysmal subarachnoid haemorrhage. The Cochrane database of systematic reviews 2007(3):Cd000277.

29. Yanpallewar SU, Hota D, Rai S, Kumar M, Acharya SB: Nimodipine attenuates biochemical, behavioral and histopathological alterations induced by acute transient and long-term bilateral common carotid occlusion in rats. Pharmacological research 2004, 49(2):143-150.

30. Li R: Hot spots and future directions of research on the neuroprotective effects of nimodipine. Neural regeneration research 2014, 9(21):1933-1938.

31. Scheller C, Wienke A, Wurm F, Simmermacher S, Rampp S, Prell J, Rachinger J, Scheller K, Koman G, Strauss $C$ et al: Neuroprotective efficacy of prophylactic enteral and parenteral nimodipine treatment in vestibular schwannoma surgery: a comparative study. Journal of neurological surgery Part $A$, Central European neurosurgery 2014, 75(4):251-258.

32. Hillard CJ, Ho WS, Thompson J, Gauthier KM, Wheelock CE, Huang H, Hammock BD: Inhibition of 2arachidonoylglycerol catabolism modulates vasoconstriction of rat middle cerebral artery by the thromboxane mimetic, U-46619. British journal of pharmacology 2007, 152(5):691-698.

33. Deshaies EM, Boulos AS, Drazin D, Popp AJ: Evidence-based pharmacotherapy for cerebral vasospasm. Neurological research 2009, 31(6):615-620.

34. Schmid-Elsaesser R, Kunz M, Zausinger S, Prueckner S, Briegel J, Steiger HJ: Intravenous magnesium versus nimodipine in the treatment of patients with aneurysmal subarachnoid hemorrhage: a randomized study. Neurosurgery 2006, 58(6):1054-1065; discussion 1054-1065.

35. Chen Y, Chen F, Yin D, Shao Q, Hu F, Chen J, Xiong Y: Two Internal Carotid Aneurysms After a Car Accident in a Young Man. World neurosurgery 2020, 134:58-61.

36. Harrigan MR, Newell DW, Alexandrov AV: Cerebral Vasospasm after Subarachnoid Hemorrhage: WileyDlackwell; 2003.

37. Dorsch NW: Therapeutic approaches to vasospasm in subarachnoid hemorrhage. Current opinion in critical care 2002, 8(2):128-133.

38. Morgan MK, Jonker B, Finfer S, Harrington T, Dorsch NW: Aggressive management of aneurysmal subarachnoid haemorrhage based on a papaverine angioplasty protocol. Journal of clinical neuroscience : official journal of the Neurosurgical Society of Australasia 2000, 7(4):305-308.

39. Can M, Kahyaoğlu O, Çolak I, Aydin Y: Predictive value of transcranial Doppler to detect clinical vasospasm in patients with aneurysmal subarachnoid haemorrhage; 2008. 
40. Lindegaard KF, Nornes H, Bakke SJ, Sorteberg W, Nakstad P: Cerebral vasospasm diagnosis by means of angiography and blood velocity measurements. Acta neurochirurgica 1989, 100(1-2):1224.

41. Aaslid R, Huber P, Nornes $\mathrm{H}$ : Evaluation of cerebrovascular spasm with transcranial Doppler ultrasound. Journal of neurosurgery 1984, 60(1):37-41.

42. Seiler RW, Nirkko AC: Effect of nimodipine on cerebrovascular response to $\mathrm{CO} 2$ in asymptomatic individuals and patients with subarachnoid hemorrhage: a transcranial Doppler ultrasound study. Neurosurgery 1990, 27(2):247-251.

43. Clyde BL, Resnick DK, Yonas H, Smith HA, Kaufmann AM: The relationship of blood velocity as measured by transcranial doppler ultrasonography to cerebral blood flow as determined by stable xenon computed tomographic studies after aneurysmal subarachnoid hemorrhage. Neurosurgery 1996, 38(5):896-904; discussion 904-895.

\section{Tables}

Table 1. Modified Fisher Scale (brain on the day of surgery)

\begin{tabular}{lccccc}
\hline \multirow{2}{*}{ Groups } & \multicolumn{4}{c}{ Modified Fisher Scale (grade) } & \multirow{2}{*}{ Total } \\
\cline { 2 - 5 } & I & II & III & IV & \\
\hline Treatment & 29 & 12 & 10 & 1 & 52 \\
Control & 28 & 9 & 4 & 1 & 42 \\
Total & 57 & 21 & 14 & 2 & 94 \\
\hline
\end{tabular}

$P=0.5774$

Table 2. Comparison of CVS between the two groups

\begin{tabular}{llll}
\hline Groups & CVS & No CVS & Total \\
\hline Treatment & 13 & 39 & 52 \\
Control & 19 & 23 & 42 \\
Total & 32 & 62 & 94 \\
\hline
\end{tabular}

$P=0.0395$

Table 3. Comparison of MCA velocity between groups (cm/s) (mean \pm SD) 


\begin{tabular}{llllllll}
\hline Groups & Cases & Prior to treatment & 1 day & 3 days & 5 days & 7 days & 14 days \\
\hline Treatment & 52 & $98.8 \pm 34.9$ & $101.6 \pm 32.2$ & $99.3 \pm 32.0$ & $99.4 \pm 32.9$ & $103.5 \pm 38.5$ & $104.8 \pm 35.9$ \\
Control & 42 & $96.9 \pm 29.6$ & $121.4 \pm 33.7^{*}$ & $129.0 \pm 43.4^{*}$ & $135.6 \pm 46.1^{*}$ & $154.5 \pm 42.3^{*}$ & $136.9 \pm 49.6^{*}$ \\
\hline
\end{tabular}

*compared with prior to the treatment $P<0.05$.

Table 4. Comparison of GOS between the two groups.

\begin{tabular}{llllllll}
\hline \multirow{2}{*}{ Groups } & \multicolumn{4}{c}{ GOS scale (grade) } & \multirow{2}{*}{ Total } \\
\cline { 2 - 5 } & I & II & III & IV & V & \\
\hline Treatment & 0 & 3 & 6 & 16 & 27 & 52 \\
Control & 1 & 2 & 12 & 17 & 10 & 42 \\
Total & 1 & 5 & 18 & 33 & 37 & 94 \\
\hline
\end{tabular}

$P=0.0389$

\section{Figures}
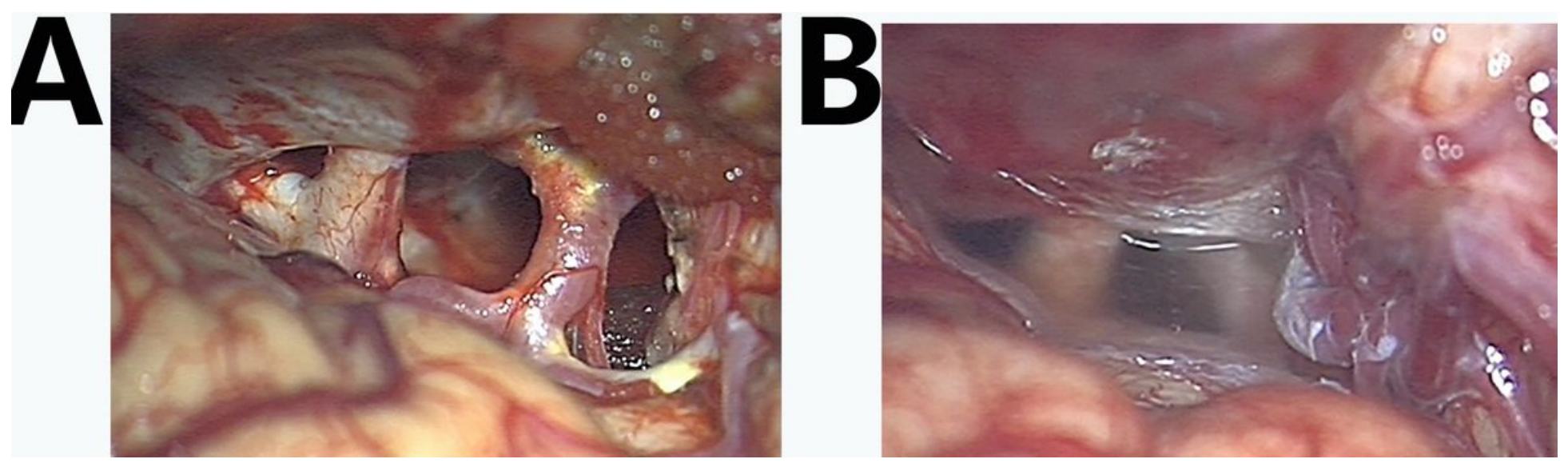

\section{Figure 1}

A: The exposure of the optic nerve and the MCA in the sellar region operation. LICA is the left ICA. LMCA is the left MCA. B: Nimodipine lavage of the optic nerve and MCA in the sellar region operation. LICA is left ICA. 

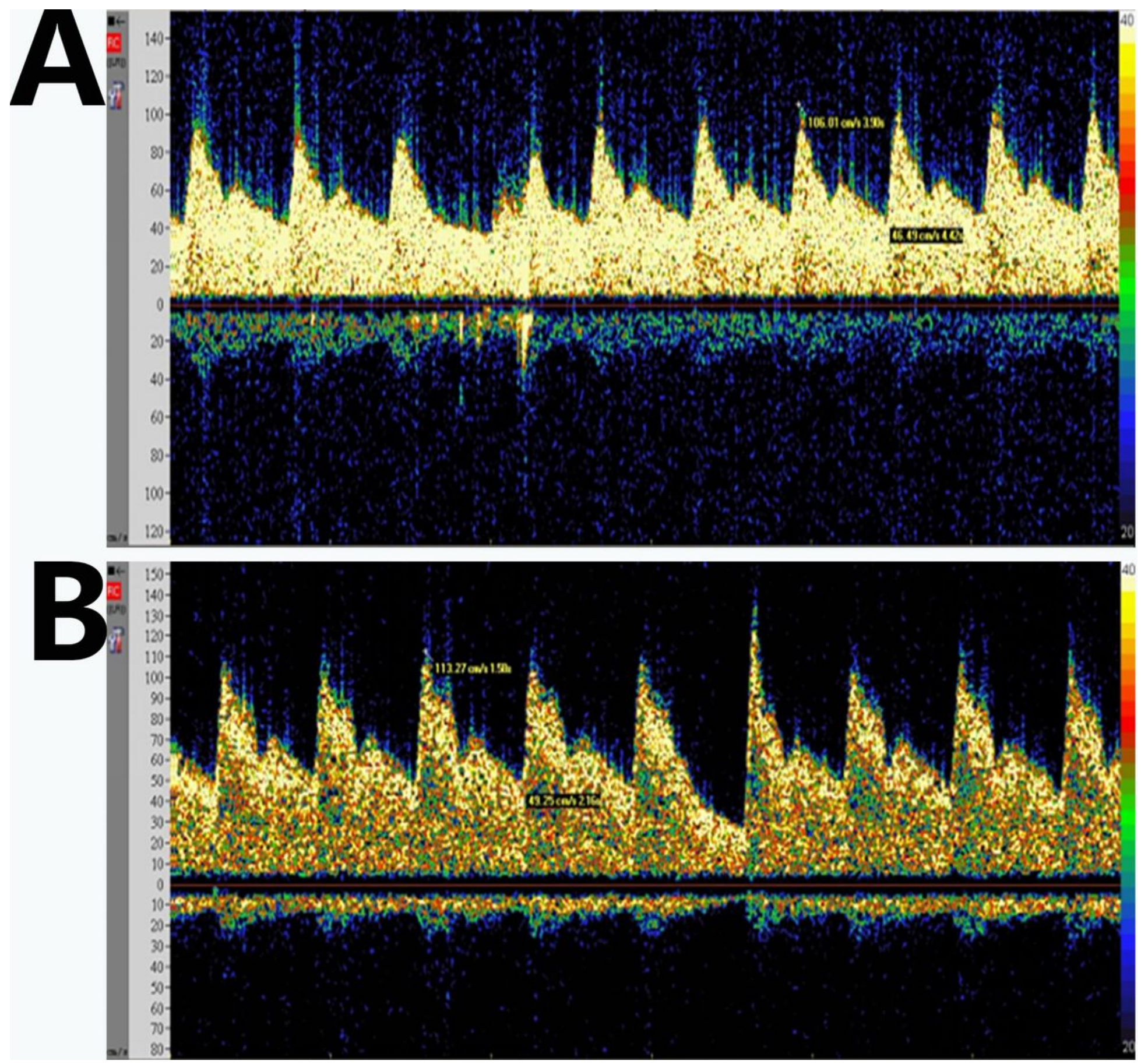

Figure 2

A: TDU examination of the treatment group prior to surgery. The MCA velocity was $106 \mathrm{~cm} / \mathrm{second}$. B: TDU examination of the treatment group after surgery. The MCA velocity was $113 \mathrm{~cm} / \mathrm{second}$. 

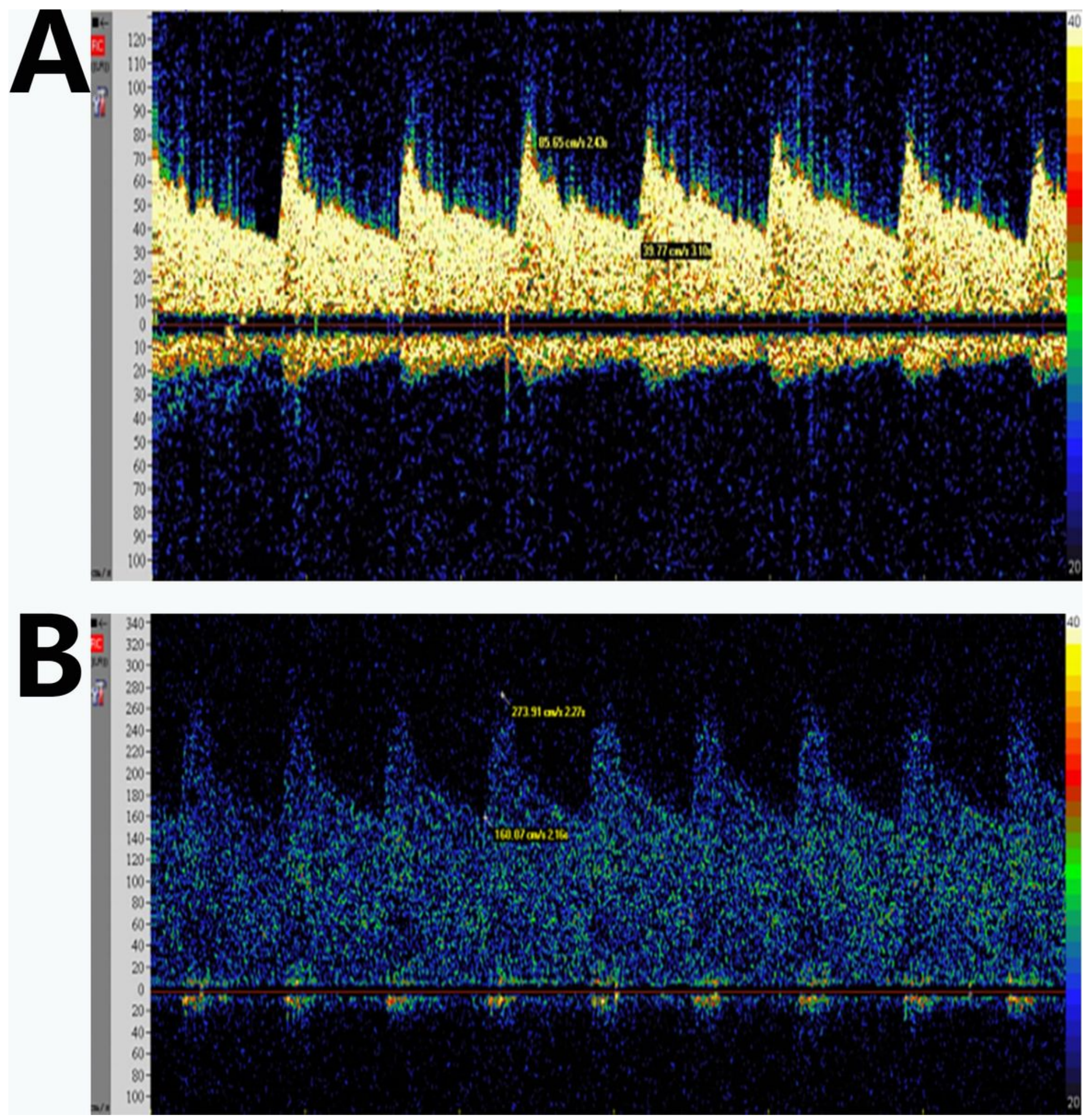

\section{Figure 3}

A: TDU examination of the control group prior to surgery. The MCA velocity was $85 \mathrm{~cm} /$ second. B: TDU examination of the control group after surgery. The MCA velocity was $273 \mathrm{~cm} /$ second. 

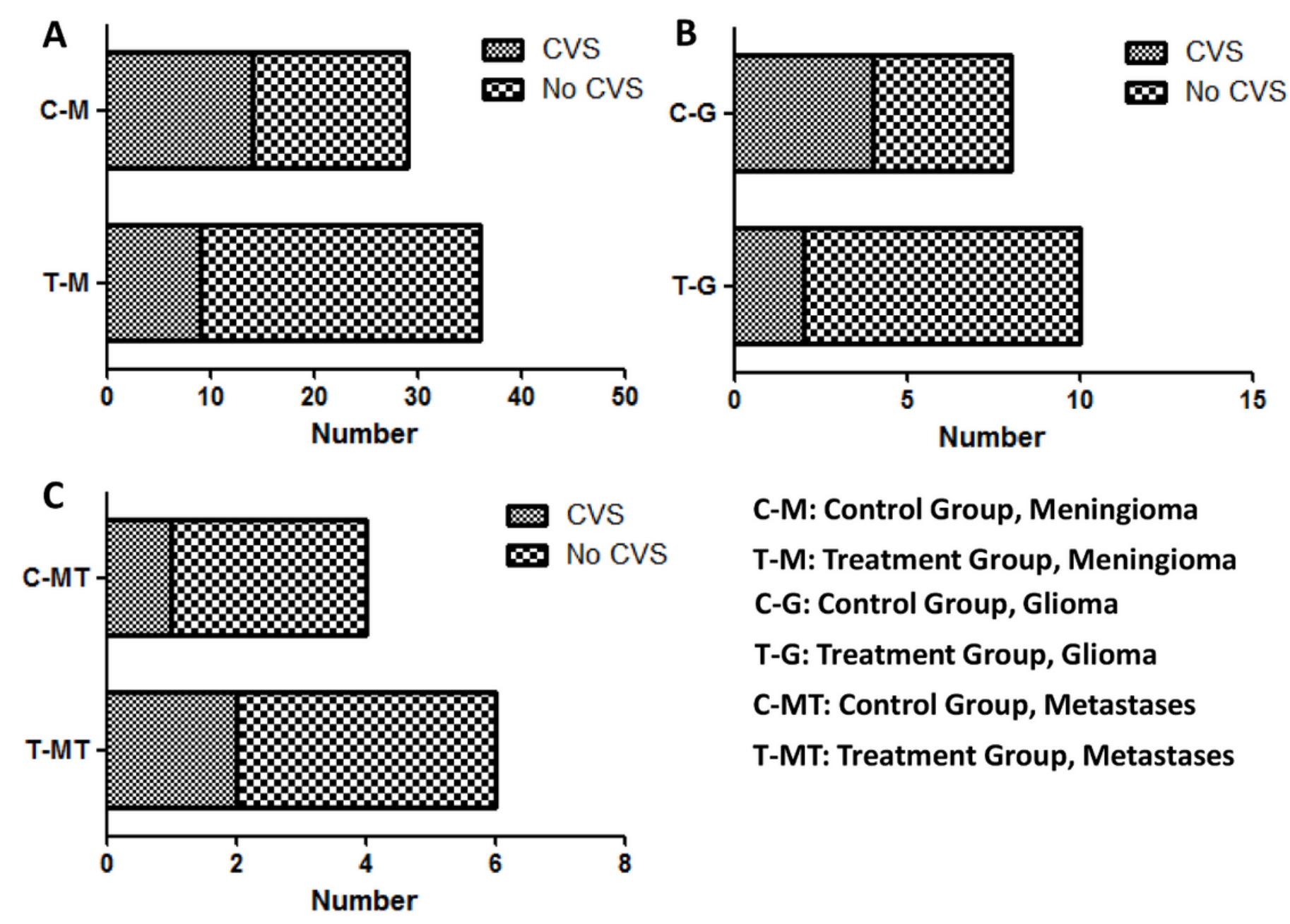

C-M: Control Group, Meningioma

T-M: Treatment Group, Meningioma

C-G: Control Group, Glioma

T-G: Treatment Group, Glioma

C-MT: Control Group, Metastases

T-MT: Treatment Group, Metastases

Figure 4

A. Compare CVS of meningioma patients between the nimodipine treatment group and the normal saline group, the occurrence of CVS was no significant difference. $p=0.0511$. B. Compare CVS of glioma patients between two groups, the occurrence of CVS was no significant difference. $p=0.1797$. C. Compare CVS of metastases patients between two groups, the occurrence of CVS was no significant difference. $\mathrm{p}=0.7782$. 